\title{
Theo-Medicine a Proposed New Field of Medicine
}

\section{Tapan K Chaudhuri*, Tushar K Chowdhury, Tandra R Chaudhuri, Taposh K Chowdhury, Bulu R Chowdhury}

Chowdhury Spiritual Research Center, Hampton, Virginia, USA

*Corresponding Author: Tapan K Chaudhuri, Professor, Chowdhury Spiritual Research Center, Hampton, Virginia, USA.

E-mail: tkchaudhuri44@gmail.com

Received: July 22, 2019; Published: July 24, 2019

DOI: $10.31080 /$ ASPS.2019.03.0354

There is ample evidence in the literature of the effects of worship, prayer and meditation on the human anatomy, physiology, biochemistry, biophysics, pathology, pharmacology, genetics, psychology [1-3] and on recovery from medical, surgical and psychiatric illnesses [4-8].

The mechanism of action of these effects is mediated through the electromagnetic energy of the human mind $[9,10]$ which in turn is acquired by wireless transmission from the original energy source of Almighty God [11] to the human mind as a result of worship, prayer and meditation.

Therefore there should be subspecialty in all medical disciplines such as Theo-Anatomy, Theo-Physiology, Theo-Pharmacology, Theo-Genetics, Theo-Psychology in basic sciences and TheoMedicine, Theo-Surgery, Theo-Psychiatry, Theo-Neurology in clinical sciences.

These subspecialties should be introduced in the medical school curriculum because if physicians, in addition to applying their materialistic knowledge of medical science in treating patients, can also apply their spiritual knowledge by praying to God along with the prayer by the patients and/or their families, more patients can be cured.

\section{Bibliography}

1. Lazar SW., et al. "Meditation experience is associated with increased cortical thickness". Neuroreport 16 (2005): 18931897.

2. Travis F and Arenander A. "Cross-sectional and longitudinal study of effects of Transcendental Meditation practice on interhemispheric frontal asymmetry and frontal coherence". International Journal of Neuroscience 116 (2006): 1519-1538.

3. Jevning R., et al. "The physiology of meditation: A review; A wakeful hypometabolic integrated response". Neuroscience and Biobehavioral Reviews 16.3 (1992): 415-424.
4. Dusek JA., et al. "Study of the therapeutic effects of intercessory prayer (STEP): Study design and research methods". American Heart Journal 143 (2002): 577-584.

5. Leibovici L. "Effects of remote, retroactive intercessory prayer on outcomes in patients with bloodstream infection: In randomized controlled trial". BMJ 323 (2001): 1450-1451.

6. Bonadonna R. "Meditation's impact on chronic illness". Holistic Nursing Practice 17.6 (2003): 309-319.

7. Richmond JA., et al. "The use of mind-body medicine and prayer among adult patients with chronic hepatitis C". Gastroenterology Nursing 33 (2010): 210-216.

8. Chaudhuri TK and Chowdhury Taposh K. "Effect of Worship, Prayer and Meditation on the recovery from septic shock" Unpublished data.

9. Chaudhuri TK., et al. Book - Electromagnetic Energy of the Human Mind. Publisher - Createspace, USA, (2017).

10. Chaudhuri TK., et al. "Effect of Electromagnetic Radiation Emanating from the Human Mind on Brain Tumor". Journal of Nuclear Medicine and Radiation Therapy S9 (2018): 004.

11. Chaudhuri TK., et al. Book - Physics of God, Universe, Human Kind and Peace in Family. Publisher - iUniverse, USA (2015).

Volume 3 Issue 8 August 2019

(C) All rights are reserved by Tapan K Chaudhuri., et al. 